\section{Animal welfare: data from an online consultation}

\author{
Paola Sechi, Chiara Baldinelli, Maria F. \\ Iulietto, Beniamino T. Cenci Goga \\ Laboratory of Food Inspection, \\ Department of Veterinary Medicine, \\ University of Perugia, Perugia, Italy
}

\begin{abstract}
This paper analyses data obtained from an online survey related to animal welfare and religious slaughter topics. The questionnaire was conducted with the purpose of examining the purchase behaviour of a group of consumers (with different religious orientation) and their views on animal protection and ritual slaughter. The main results of the consultation were two. The first evidenced the respondents' great interest about the question on animal welfare, which is in accordance with the growing interest of European citizens concerning this issue. The second was the demand for a more transparent labelling of animal products, which would also reflect animal welfare and the slaughter method used. These results are in contrast with marketing analysis, which finds that consumers want to only receive positive information. Paradoxically, the more information is transmitted to reassure consumers, the higher is the risk to alarm them.
\end{abstract}

\section{Introduction}

Animal welfare is not only an emotive issue surrounding meat production but also an imperative human obligation; European citizens are becoming more aware of animal protection and the effect on meat quality (Kehlbacher et al., 2012). Not only farm animal rearing but also transport and slaughtering constitute a strong impact in meat production and modern consumers' expectations. The European Commission, during last decade, carried out several surveys on food quality and, on detail, the Eurobarometer survey (Special Eurobarometer, 2007) demonstrated an evident consumers' interest in animal welfare friendly products. Those products represent food of animal origin obtained from animal reared more respectfully. Among the totality, $62 \%$ of the people involved in the questionnaire expressed their willingness in buying high welfare animal-based products (Cenci Goga and Fermani, 2010).

Welfare labelling constitutes an impressive way to communicate the attempts in improving farm animals' life and slaughtering conditions in order to contrast the crisis of consumers confidence of the last years (Cenci Goga and Fermani, 2010).

The concept of the animal welfare passes through the entire life of livestock and the European Community shares this value transmitting legislation for the animal protection. The proposal and implementation of these rules are indicative of the growing interest of Europeans in this topic and the increased concern for the implications that intensive farming has on animal health, welfare, and health safety of their meat.

In recent decades, there have been a series of increasingly detailed rules on the welfare and protection of animals also during slaughter. In Italy, the protection of animals from unnecessary suffering and cruelty represents a trend in legislation, starting from the Criminal Code of 1889 article 491 including punishment for the mistreatment of animals to actual legislation.

With Regulation No. 1009/2009 (European Commission, 2009) the Council of the European Union considered it necessary to amend European legislation regarding the protection of animals during slaughter to adapt to technological advances and scientific discoveries and to respond to the growing interest of Europeans for the improvement of animal welfare. The regulation came into effect on December 2009, was applied from January 1, 2013, and repealed Council Directive 93/119/EC of December 22 (European Commission, 1993), 1993 on the protection of animals at the time of slaughter or culling. The main items dealt with in Regulation No. 1099/2009 are as follows: greater responsibility is given to operators regarding animal welfare; the introduction of the concept of correct stunning indicators; the obligation to obtain a certificate of qualification from staff involved in handling animals and/or the slaughter; the introduction of responsible animal welfare; the importance of standard operating procedures; and the requirement of prior approval of slaughterhouses, including aspects relating to animal welfare, by competent authorities. All these aspects are meant to increase animal welfare during slaughter. In the context of Regulation (EC) No. 1099/2009 (European Commission, 2009), the question of ritual slaughter had a marginal role as Community rules on ritual slaughter have been transposed differently depending on the national situation. Considering that national rules take into account dimensions that go beyond the objectives of this regulation, it is important to maintain the special dispensation from stunning of animals before slaughter while granting a certain level of subsidiarity to each Member State. Compared to the previous legislation, the new regulation adopted a legal definition of ritual slaughter, intended as a series of acts related
Correspondence: Paola Sechi, Laboratory of Food Inspection, Department of Veterinary Medicine, University of Perugia, via San Costanzo, 06126 Perugia, Italy.

Tel: +39.075.5857929 - Fax: +39.075 .5857976$

E-mail: paolasechi@supereva.it

Key words: Animal welfare; Consumers; Religious slaughter.

Received for publication: 26 August 2015.

Revision received: 2 October 2015

Accepted for publication: 3 October 2015

This work is licensed under a Creative Commons Attribution 3.0 License (by-nc 3.0).

(C) Copyright P. Sechi, et al., 2015

Licensee PAGEPress, Italy

Italian Journal of Food Safety 2015; 4:5504

doi:10.4081/ijfs.2015.5504

to the slaughter of animals prescribed by a religion. This definition takes into account the religious slaughter in all its aspects, not only for jugulating an animal without prior stunning. It is noted that not all anatomical parts of ritually slaughtered animals are used for the production of Halal or Kosher food. Finally, although the regulation prohibits cattle restraint systems prior to hanging, there is an exception in the case of ritually slaughtered animals provided that such devices are adapted to the size of the animal and are not equipped with a device that limits the lateral and vertical movements of the animal's head. The current regulation of religious slaughter is based on two principles, which are considered to be confrontational. On the one hand, there is a growing awareness of animal welfare that led lawmakers to ban slaughter without prior stunning on the grounds that such methods cause unnecessary pain to the animal. On the other hand, there is the protection of religious freedom. Member States of the European Union have balanced these two interests in different ways, and these differences have led to a variety of solutions. Belgium, Bulgaria, the Czech Republic, France, Germany, Greece, Hungary, Ireland, Italy, Lithuania, Luxembourg, Malta, the Netherlands, Poland, Portugal, the Republic of Cyprus, Romania, Slovenia, Spain, and the United Kingdom allow religious slaughter without prior stunning provided that a number of legal requirements are respected. This also applies to Denmark with the exception of the slaughter of cattle, which allows post cut stunning, which is stunning after jugulation. Austria, Denmark, Estonia, and Slovakia allow religious slaughter of cattle without stunning provided that a method of stunning is used after jugulation (post cut stunning). In Finland (with the exception of the province of Åland), while post cut stunning 
is not formally prescribed, they ruled that animals must be stunned at the same time as the severing of the neck vessels. Latvia, Sweden, and the Finnish province of Åland (which has a separate legal system), does not allow the execution of religious slaughter without prior stunning (Dialrel, 2009).

Within the framework of the Dialrel project, in regards to religious slaughter financed by the European Community and divided into six under-projects, several documents have been formulated (Bottoni and Ferrari, 2010; Velarde et al., 2010, 2014; Bergeaud-Blackler et al., 2012). These documents contain a series of recommendations for the proper practice of religious slaughter. These works have opened the way for further dialogue on the question of religious slaughter between the different parties concerned because, even though the information on animal welfare and methods has increased, few studies have thus far taken into consideration other important aspects such as the size of consumption and consumer concerns. The issue of consumption and consumers is very important in light of the recent interest in this theme by consumers of Halal and Kosher products. In recent years, the demand for products that meet requirements for religious slaughter has increased and the market share of these products is, today, quite consistent. In order to remedy the lack of information in this area, the third Dialrel underproject has explored these aspects using the methodology of focus groups in some European Union countries. Among the topics covered were consumer opinions of Muslim and Jewish people about the availability of Halal and Kosher products in their country, on the certification and labelling, and on the problem of false labelling of these products.

In our project it was decided to investigate the issues of consumers but in a context different from those addressed in the Dialrel project. The aim of the survey was to underline the consumers' perception of animal protection and the impact on their choices. The intent was to reconcile the consumer concerns on animal welfare in the food chain with the needs of the market.

\section{Materials and Methods}

In order to investigate the attitudes of consumers to the welfare and protection of farmed animals, everyday purchasing practices (especially in relation to animal welfare), consumer expectations of the market, and personal knowledge on religious slaughter, an anonymous computerized questionnaire was created. The questionnaire was developed using the GoogleForms application (www.google.it) and was then made accessible on-line at the follow- ing link: https:/docs.google.com/spreadsheet/ viewform?formkey=dEInNFN0cXp4MXVwd2pC NFFiMlloSIE6MQ

The participants were mostly of the Christian religion, only $2 \%$ of the subjects were Jewish or Muslim. The choice to use a computerized questionnaire instead of focus groups made possible to reach a larger number of interviewed. The animal welfare topics and purchasing behaviour have already been addressed under another Community project called Welfare Quality (Special Eurobarometer, $2005,2007)$ funded by the European Union.

The methodology of the questionnaire was also used for the welfare quality Community project. Our questionnaire has a four-part structure: the first part is dedicated to the background of the consumer who took part in the survey; the second focuses on knowledge of animal welfare and purchasing behaviour of respondents; the third part is devoted to religious slaughter; and the last part was left open for any ideas or comments.

The consumers' background was outlined in a series of ten questions on general information, level of education, household composition, employment, and religious orientation. Through this first phase it was possible to define the type of consumers and separate them into two categories: ordinary consumers and ethically competent consumers. The second part examined the following themes: knowledge and consideration of the conditions under which animals are kept; knowledge, importance, and the perception of animal welfare; knowledge and judgment of the consumer of the so-called animal welfare friendly products; the opinion on current labels of products of animal origin; and the perception of the existing laws on consumer welfare of farmed animals. The third part was preceded by a brief definition of traditional slaughter, the worldwide way of slaughtering according to each country rules, and religious slaughter, which constitutes the practical application of ritual precepts handed down during centuries by Torah and Koran. This addition was needed in order to permit even those who were not aware of the different existing methods of slaughter to respond to questions about ritual slaughter.

\section{Results}

During the survey 320 people replied to the questionnaire. For each question, the results were examined in terms of percentages and relation to socio-demographic variables of consumers interviewed. In addition, answers to some questions were cross-checked with additional classification variables. More than half of the people who answered the questionnaire were under the age of 30 (57.5\%) with a slight predominance of female individuals (60\%). Almost all of the respondents were of Italian nationality (97\%).

The initial questions of the questionnaire defined the type of consumer based on the family organization and the frequency of buying food. The purpose is to figure out if the consumer is buying only for himself/herself or buying food for a family. From this comparison, it is possible to assume that those married or cohabiting buy food regularly for their families (41\% always; $42 \%$ often) and to a lesser extent singles (37\% always; $25 \%$ often). In other cases, there are even lower percentages (22\% always; $24 \%$, often). Investigation of the dietary habits of the subjects on the consumption of meat on a weekly basis found that almost all of the respondents habitually consumed meat (97\%). Of these, $42 \%$ ate meat 2 3 times a week, $32 \%$ 4-5 times per week and $12 \%$ more than 5 times a week. In the second part of the questionnaire several topics were addressed. The level of knowledge of respondents about the conditions in which animals are reared is of considerable importance. The survey results are in line with the emphasis by the European Commission in respect of animal welfare (Miele et al., 2010a, 2010b). Eighty-two per cent of respondents have visited a farm at least once and, of these, $58 \%$ say they went there more than three times. Socio-demographic analysis of responses shows interesting aspects: people between 50 and 60 years old have been on farms more often (94\%) than subjects of other age categories, as well as more males (86\%) than females. It is interesting to note that the subjects who most frequently visited a farm breeding animals were those who do not eat meat and, in second place, those who eat meat once a week. A majority of respondents (89\%) said they have at least a basic knowledge of farming conditions while only $11 \%$ declared to know nothing. The cross-analysis of results with social and demographic factors shows that the level of knowledge of the conditions in which animals are reared is partly related to some of these factors. As for the age and sex, males between 50 and 60 years are more knowledgeable about farming conditions. Non-Italian subjects have a greater knowledge of the subject than the Italians (100\%). A link between the education level of respondents and their knowledge of farming conditions was not detected. In fact, an analysis of the results showed that the more informed on the subject categories are people with an average education (100\%). With regard to religious orientation, all followers of Judaism claim to have a high knowledge of the topic, followed by Muslims and atheists. A comparison between the wish to receive more information and level of knowledge of farming conditions shows that the higher the level of knowledge of the topic the greater is the desire 
to receive more information about it.

Particular importance was given to the religious orientation of consumers, particularly with regard to the last part of the questionnaire that focuses on religious slaughter. Almost two-thirds of those claimed to be Christian while only $2 \%$ were declared to be Jewish or Muslim. The survey results are in line with the focus of the European Commission in relation to animal welfare where great interest has also been encountered in respect to the issue of religious slaughter (Miele et al., 2010a, 2010b). The level of importance given to the protection of the welfare of intensively reared livestock is one of the most obvious results of the survey with the average value of the responses of 8.9 in an importance scale from 1 to 10 . Moreover, the general tendency is to consider farm animal welfare from very important or important. The latter opinion was uninfluenced by social or demographic factors. Also, the importance given to animal welfare grows with the increase of knowledge of respondents on the topic itself, the frequency of visits to a company that breeds the animals, and the conditions in which animals are reared. Animal welfare is judged differently for the various species considered in the questionnaire: the greater degree of concern relates to the conditions of laying hens and pigs while the opinion on the welfare of dairy cows is better although not by much. While the majority of respondents are of the opinion that the welfare of farm animals has improved over the last ten years, there is a strong belief that further improvements are needed on the level of protection and animal welfare. There is a need to increase animal welfare for both ethical reasons and as a prerequisite for health safety of products of animal origin. A slight majority of consumers (55\%) believe that food quality is derived from animals raised with high standards of comfort while $45 \%$ of respondents disagree. Results underline most consumers' belief that better products come from animals raised in respect of animal welfare (according to the concept that if the animal is well managed it produces more and better) but at the same time others do not agree that quality products come from animals raised with greater respect. Not all respondents for whom there is a correlation between quality/food safety and animal welfare believe in the equation: quality=higher food welfare standards ( $40 \%$ of subjects do not believe in this equation). Only $20 \%$ of respondents think that their role as a consumer can better ensure the improvement of animal welfare, almost all consumers have confidence in their ability to influence animal welfare through their purchasing behaviour. The poll showed that $60 \%$ of respondents consider themselves as critical thinking consumers, whose food purchases are rational and weight- ed, while $40 \%$ are defined as ordinary consumers making choices dictated by daily routine without associating a product to the conditions in which the animal was reared, transported, or slaughtered. The three main parameters on which interviewed consumers based their purchases were found to be the country of production (69\%), the price $(65 \%)$, and ingredients (61\%). The presence of additives is a fairly evaluated parameter (38\%) based on the number of responses.

Animal welfare received $27 \%$ of the vote. Despite the lower percentage of answers given to animal welfare, breeding and production methods occupy fourth place with $53 \%$ of the responses that a certain index evaluation of elements connected to animal welfare was taken into account. The production and farming methods received $53 \%$ of the responses. Animal welfare is only in the sixth position, as a percentage, with $26 \%$ of the vote. When asked if animal welfare is considered when buying meat, almost two-thirds of respondents (64\%) said they consider this topic quite often or sometimes. However, when comparing this result with that relating to the interest in animal welfare, the survey showed that despite almost all of those polled having a high regard for farm animal welfare, a certain percentage (33\%) claimed to never or very rarely think of animal welfare when buying meat. The analysis of the results in relation to socio-demographic variables shows that those aged between 50 and 60 years have a greater consideration of animal welfare at the time of purchase of food, as well as the subjects of Italian nationality more than non-Italians (56\% of Italians do not claim to assess animal welfare most of the time). Regarding the education, $67 \%$ of subjects with an average education state they assess animal welfare most of the time. As regards the so-called animal welfare friendly products, namely food of animal origin derived from animals reared with greater respect for animal welfare, the survey has highlighted considerable interest in these products. The assessment of the main reasons why to buy these foods shows that the idea that consumers have about animal welfare friendly products is anthropocentric in part because animal welfare seems to be considered a very important indicator of features such as health safety and quality of the meat. There is also an ethical motivation to buy these products: animal welfare friendly products originate from animals that do not suffer ( $55 \%$ of the vote) and so buying these, help farmers treat their animals better (49\%). Seventy-six per cent of respondents stated that the current labels of products of animal origin do not identify animal welfare friendly products. Labelling would represent the best method for identification of animal welfare friendly products in text form or with logos on the package. Sixty per cent of respondents said that during the purchase of eggs, milk or meat, they never or rarely identify if the product is animal welfare respectful through labels. For $42 \%$ of these identification is never possible. It is important to understand what consumers think of the information on the labels of products of animal origin without special reference to welfare friendly products. Results show that a majority of respondents have a negative view of such information; in fact, $84 \%$ believe that they are not clear and transparent. This lack of identification could help influence the ability of those subjects that do not assess the animal welfare when they buy food to consider it in their food choices. It is interesting to note how the subjects that can more easily identify the labelled welfare friend$l y$ products are those who do not eat meat (60\%) or, at most, once a week (54\%).

The questionnaire asked the consumers, who is in the best position to ensure that products of animal origin are produced in a welfare friendly way. Most selected; the breeder, with $48 \%$ of the votes, and then veterinary surgeons with $45 \%$ of the responses. The European Commission chosen by $34 \%$ of respondents occupies the third place. Even the Government and consumers seem to have an important role in ensuring the welfare, as mentioned by $44 \%$ of consumers. Finally, the food processing industry, associations, protectionist, restaurants and food shops seem to have a minor role in ensuring animal welfare. In general, it is possible to conclude that, according to consumers interviewed, farmers are the main people responsible for the welfare of their cattle, are assisted by veterinary surgeons, and all is regulated and supervised by the European Commission and the national Government. Breeders and veterinarians, probably, are seen as figures that come into regular contact with animals and therefore are in the ideal situation to make necessary changes to improve the welfare of farmed animals.

The survey showed that the surveyed consumers tend to overestimate their willingness to purchase products with higher standards of animal welfare since the willingness to pay higher prices, often required for these foods, and to change the habitual place of ethical motivations is not fully put into practice when food shopping. The issue of labelling is particularly noticed, as evidenced by the fact that for respondents this would be the best method of identification of animal welfare friendly products, both in the form of text and in the form of logos on product packaging. As many as $77 \%$ of those polled believe that there is a sufficient choice of animal welfare-friendly food products in supermarkets. This little safety, along with $12 \%$ of subjects who claim not to know if the presence of these products on the market is sufficient or not, is indicative of poor and confused knowledge probably due to the scarcity of 
information and products available for consumers of these products. The purpose of the survey was to find out whether, in practice, consumers would acquire these products, the possible reasons why they buy them, and under what conditions, such as if they are willing to accept a higher price and to change their purchasing habits because of animal welfare considerations. The answers to these questions are quite positive with $97 \%$ of consumers claiming to be inclined to purchase animal welfare friendly products. According to the consumers surveyed, the main reason why they buy animal welfare friendly products is the fact that they come from healthier animals (69\%), followed by those that originate from animals that do not suffer (55\%). For $49 \%$ of respondents a valid reason to buy these products is to help farmers that treat animals better. The quality (46\%) and safety of health products (40\%) represent, respectively, the fourth and fifth reasons of choice and, probably, are linked to the great perception that animal welfare friendly products originate from healthier animals. Evaluated together, these findings suggest that consumer purchasing behaviour is indeed influenced by the idea that animal welfare friendly products give consumers the same benefits in terms of health and quality of life, but also begins to help develop a better animal welfare ethic.

The introduction of stricter animal welfare has resulted in increased costs for farmers. The general thought is that farmers should be compensated for the high production costs related to the improvement of animal welfare. Eighty-eight per cent of respondents support this idea, and about half of them are certainly convinced by this concept. More than half of those surveyed think that animal welfare within the EU is better than in other parts of the world. A quarter believed that the security level is about the same as other parts of the world, while only $3 \%$ of respondents think it is worse than in other parts of the world. Eighty-six per cent of respondents believe that non-EU countries should respect the same conditions as applied to animal welfare in the European Union and that the disparities between the conditions of animal welfare in the European Union and the rest of the world should be reduced. This view is strongly supported by $50 \%$ of respondents and is indicative, firstly, of the importance attached to animal welfare and, secondly, may also reflect an economic component: the introduction of stricter animal welfare standards can result in large consequences for competitiveness in the world market of products of animal origin obtained in European Union countries more respectful of animal welfare. The majority of consumers believe that European legislation concerning animal welfare exist for slaughter (74\%) and the transport of animals (69\%). Fifty-two per cent are less convinced that the existence of this kind of legislation modifies the conditions in which animals are kept. Finally, $11 \%$ of respondents do not know if there is a European legislation in this field.

In the questionnaire, the theme of religious slaughter was faced with a different perspective from that used in studies by Dialrel: the opinions and concerns about the welfare of animals slaughtered by religious methods and labelling of products Halal and Kosher for persons of all religions and not necessarily of Jewish or Muslim religion have been assessed. Most of the respondents said they know what religious slaughter is. The interest in receiving information on the slaughtering method used when buying meat and dairy products is one of the most interesting results that emerged from the survey. Indeed, $83 \%$ of respondents are interested in receiving such information. The inclusion of the slaughtering method used in the labelling of animal products is seen by nearly four-fifths of consumers as a way to be better protected. The problem of protecting mainly non-Muslim and non-Jewish consumers is that the meat not approved by the Jews and the Muslims, Haram or Treifa, but judged fit for consumption by a meat inspector can get into the same channel of distribution as the meat obtained by conventional slaughter and thus be consumed inadvertently by ethical consumers. More than half of respondents would consider using alternative methods of religious slaughter and this is the opinion of $50 \%$ of Muslim and Jewish consumers. Thirty-two percent of subjects, among these $50 \%$ of Muslims surveyed, are not opposed to religious slaughter but think something could be done to improve the welfare of animals slaughtered in accordance with this practice. Finally, for $7 \%$ of respondents, the traditions must be respected even if they are unpleasant.

\section{Discussion and Conclusions}

The two main findings from the survey are the great importance that consumers give to the protection of animal welfare and the need for more and clearer information on animal welfare and the slaughtering method used. The consumers surveyed claim to be sufficiently informed and ethically involved. What is missing is clear and transparent information on the products they buy and that the lack of such information negatively affects their ability to choose.

In spite of the people interviewed having stated to be well informed about the conditions in which animals are raised, they have also expressed a desire for more information on this subject. About nine out of ten (89\%) say they have at least a basic knowledge of farming conditions with about half of the subjects admitting to having good familiarity with the topic. Given the importance of the issue, it is not surprising that almost all respondents (94\%) would like to be more informed about the conditions in which animals are reared. The main source of information for the farming conditions was found to be the Internet with $68 \%$ of the vote. The information leaflets and television have achieved a broad consensus but with lower percentages. The level of importance given to the protection of the welfare of intensively farmed animals is one of the most obvious results of the survey with the average value of the responses, in a growing importance scale from 1 to 10 , of 8.9 (Kehlbacher et al., 2012). In addition, the general tendency is to consider the welfare of farm animals very important or important (Blokhuisa et al., 2008). The latter opinion is uninfluenced by social or demographic factors. Visits to farms that raise animals seem to increase awareness and consumer concern for animal welfare: in fact, the people who visited a farm at least once have a greater consideration of animal welfare even at the moment of purchase of products of animal origin. These statements, related to the frequency of visiting a breeder, show the potential impact that an awareness campaign for animal welfare may have that begins with visits to companies that breed farm animals (even with so-called $e d u$ cational farms) as a first step. The comparison with reality would appear, in fact, to have a positive impact on the consideration of animal welfare. The breeder (48\%) is considered to be the figure most capable of ensuring the necessary improvements in animal welfare with veterinary surgeons (45\%), the European Commission (34\%) and the Government (24\%) seen as figures with an important supplementary role. Although only $20 \%$ of respondents think that their role as consumers can better ensure the improvement of animal welfare, almost two out of three consumers have confidence in their ability to influence animal welfare through their purchasing behaviour. Based on the results of our investigation, the growing consideration of animal welfare and the demand for more information on the slaughtering method used draws attention to the labels of foods of animal origin. These issues may affect the acceptability of the product in the market (contrary to the rules of marketing which are based on providing positive information) (Velarde et al., 2008).

The problem is to find the right formula to indicate the method of slaughter on the packaging of foodstuffs of animal origin without confusing the consumer. Information strategies should take into account the fact that the pattern of consumption of food occurs along a spectrum from ordinary to critical whereby the 
best solution might be represented by a system of tiered information, which can satisfy different needs. Beyond the label information is also important (Miele et al., 2010a, 2010b). Awareness of farm animal welfare in schools, visits to farms, the conscious use of the Internet and the media, and visits to a slaughterhouse could provide this information.

Respondents have a very clear opinion on whether or not farmers should be paid for the higher costs of production related to the breeding of animals under better welfare conditions. In fact, almost nine out of ten consumers agree with the principle that financial compensation should be used to relieve any increased costs associated with the improvement of animal welfare. There are two ways to ensure an adequate level of income to producers: the increase in the cost of animal welfare friendly products and public monetary compensation (Napolitano et al., 2010; Toma et al., 2012). Within the Dialrel project, several focus groups in some European countries were conducted with participants from Muslim and Jewish religions to investigate the opinion of religious slaughter themselves, their food consumption practices, and expectations of consumers of halal and kosher products (Cenci Goga and Fermani, 2010). The objective of our survey was to evaluate the opinions and concerns on these same themes of individuals of all religions and not necessarily just of Jewish or Muslim religions. A majority of respondents said they know what religious slaughter is. There seems to be a positive correlation between those who consider animal welfare to be very important or important and knowledge of religious slaughter. The interest in receiving information on the slaughtering method used at the time of purchase of meat and dairy products is one of the most interesting results emerged from the survey. Indeed, $83 \%$ of respondents are interested in receiving such information. Religious orientation doesn't seem to affect this interest. It should be noted that the propensity to receive information on the slaughtering method used in the packaging of products of animal origin clashes with marketing rules based on providing positive information. The slaughtering method used in the labelling of animal products is seen by nearly four-fifths of the consumers as a way to be more protected. As regards the quality and health safety of products originating from animals that were slaughtered in a ritual way, $42 \%$ of consumers think that this is the same as that of products derived from animals slaughtered traditionally. Twenty-eight per cent think that this quality is lower while only $2 \%$ of consumers think that these products are of supe- rior quality. For more than half of respondents it would be appropriate to use alternative methods of religious slaughter. This is also the opinion of $50 \%$ of respondents of Muslim and Jewish faiths. A quarter of the subjects are not opposed to religious slaughter but think something could be done to improve the welfare of animals slaughtered in accordance with this practice. Included in this quarter were also $50 \%$ of Muslims surveyed. Finally, for $7 \%$ of respondents, traditions must be respected even if regrettable. It is also desirable to have an increased choice of animal welfare friendly products in supermarkets and an increased membership of producers working for wellness and ethical production.

\section{References}

Bergeaud-Blackler F, Evans A, Zivotofsky A, 2012. WP3-1 deliverable. Final report consumer and consumption issues. Halal and Kosher Focus Groups Results. Dialrel Reports ed., University of Bristol, UK. Available from: www.dialrel.eu/images/ report-consumption.pdf

Blokhuisa HJ, Keelinga LJ, Andrea Gavinelli A, Serratosa J, 2008. Animal welfare's impact on the food chain. Trends Food Sci Technol 19:S79-87.

Bottoni R, Ferrari S, 2010. Legislation regarding religious slaughter in the EU, candidate and associated countries. Dialrel Reports ed., University of Bristol, UK. Available from: dialrel.eu/images/reportlegislation.pdf

Cenci Goga BT, Fermani AG, 2010. La macellazione religiosa: protezione degli animali e produzione igienica delle carni. Point Veterinaire Italie, Milan, Italy.

Dialrel, 2009. Religious slaughter, improving knowledge and expertise through dialogue and debate on issues of welfare, legislation and socio-economic aspects. Available from: http://www.dialrel.eu/

European Commission, 1993. Council directive of 22 december 1993 on the protection of animals at the time of slaughter or killing, 93/119/EC. In: Official Journal, L 340/21, 31.12.1993.

European Commission, 2009. Council regulation of 24 september 2009 on the protection of animals at the time of killing, 1099/2009/EC. In: Official Journal, L 303/1, 18.11.2009.

Kehlbacher A, Bennett, R, Balcombe K, 2012. Measuring the consumer benefits of improving farm animal welfare to inform welfare labeling. Food Policy 37:627-33.

Miele M, Evans A, Higgin M, 2010a. Le aspettative dei consumatori. In: Cenci Goga BT, Fermani AG, eds. La macellazione religiosa. Protezione degli animali e produzione igienica delle carni. Point Veterinaire Italie ed., Milan, Italy.

Miele M, Higgin M, Evans A, 2010b. Dubbi dei consumatori, normativa e trasparenza del mercato. In: Cenci Goga BT, Fermani AG, eds. La macellazione religiosa. Protezione degli animali e produzione igienica delle carni. Point Veterinaire Italie ed., Milan, Italy, pp 69-81.

Napolitano F, Girolami A, Braghieri A, 2010. Consumer liking and willingness to pay for high welfare animalbased products. Trends Food Sci Technol 21:537-43.

Special Eurobarometer, 2005. Attitudes of consumers towards the welfare of farmed animals. 229/Wave 63.2. Availale from: ec.europa.eu/public_opinion/archives/ebs/ ebs_229_en.pdf

Special Eurobarometer, 2007. Attitudes of EU citizens towards animal welfare. 270/Wave 66.1. Available from: https://opendata.europa.eu/it/data/dataset/S470_66_1_ EBS270

Toma L, Stott, A W, Revoredo-Giha C, KupiecTeahan B, 2012. Consumers and animal welfare. A comparison between European Union countries. Appetite 58:597-607.

Velarde A, Anil H, Cenci Goga BT, Frencia JP, Lambooij B, Von Holleben K, Von Wenzlawowicz BM, Dalmau A, 2008. Religious slaughter in Europe. In: Putting the OIE standards to work: Proceedings of the 2nd OIE Global Conference on Animal Welfare, 20-22 October 2008, Cairo, Egypt. OIE-World Organisation for Animal Health, Paris, France.

Velarde A, Rodriguez P, Dalmau A, Fuentes C, Llonch $\mathrm{P}$, Von Holleben KV, Anil MH, Lambooij JB, Pleiter H, Yesildere T, CenciGoga BT, 2014. Religious slaughter: evaluation of current practices in selected countries. Meat Sci 96:278-87.

Velarde A, Rodriguez P, Fuentes C, Llonch P, Von Holleben K, Von Wenzlawowicz M, Anil H, Miele M, Cenci Goga BT, Lambooij B, Zivotofsky A, Gregory N, BergeaudBlackler F, Dalmau A, 2010. Improving animal welfare during religious slaughter. Recommendations for good practice. Dialrel Reports ed., University of Bristol, UK. Available from: http://www.dialrel. eu/images/recom-light.pdf 